\title{
Polymerase chain reaction-restriction fragment length polymorphism for characterization of Candida species causing onychomycosis
}

\author{
Noha EL-Mashad, Douaa Raafat, Ahemad Elewa and Walaa Othman* \\ Department of Clinical Pathology, Faculty of Medicine, Mansoura University, Egypt.
}

Accepted 10 May, 2013

\begin{abstract}
Traditional methods that are used to identify clinical isolates of Candida species are time-consuming and not appropriate for rapid, accurate and reliable identification. The aim of this study was to characterize Candida species isolated from fingernail onychomycosis by using polymerase chain reaction (PCR) followed by restriction fragment length polymorphism (RFLP) with three different restriction enzymes HaellI, Ddel and Bfal. 16 Candida isolates recovered from infected fingernail samples were selected and phenotypically identified by API 20C identification kit. Also, the five species were identified genotypically with PCR-RFLP analysis. 16 clinical Candida isolates comprising five species were included in this study; three Candida species were identified using conventional API 20C: C. albicans $(9 / 16), C$. parapsilosis $(3 / 16)$ and $C$. glabrata $(1 / 16)$ with three unidentified isolates. Five species were identified based on genotypic identification with PCR-RFLP analysis revealing $C$. albicans (9/16), C. parapsilosis (4/16), C. glabrata, C. guilliermondii and C. tropicalis (1/16 for each). It was concluded that the PCR-RFLP analysis of rDNA enabled more easy, rapid and precise identification of Candida species compared to phenotypic methods. RFLP analysis demonstrated that Haell is the most differentiating enzyme that distinguished $C$. albicans from non $C$. albicans species. Bfal maintained the differentiation of these non $\boldsymbol{C}$. albicans species and Ddel digestion confirmed $C$. albicans species.
\end{abstract}

Key words: Onychomycosis, Candida species, polymerase chain reaction-restriction fragment length polymorphism (PCR-RFLP).

\section{INTRODUCTION}

Onychomycosis is a fungal infection of the fingernails or toenails that cause the nails to be thickened, discolor, disfigure and even split (Roberts et al., 2003). Infection of the nail apparatus by fungus may be caused by dermatophytes, non dermatophytic moulds and /or yeasts. However, the primary cause of onychomycosis is dermatophytes. Candida species have emerged as a second-line pathogens (Jayatilake et al., 2009).
Candidal onychomycosis is increasingly found among individuals having defective immunity consequential to aging, diabetes mellitus, vascular diseases or individuals under immunosuppressive or broad spectrum antibiotics (Jayatilake et al., 2009).

Candida species are infrequent cause of toenail infections but account for 51 to $70 \%$ of fingernail infections and is more frequently seen in women 
(Ghannoum et al., 2000; Roberts et al., 2003). Although, Candida albicans is frequently isolated from onychomycosis, Candida parapsilosis is emerging as an important fingernail pathogen. However, other non albicans are recovered from fingernail infections as $C$. tropicalis and C. Iusitaniae (Taylor et al., 1999).

Current methods for the identification of Candida species represent conventional approaches are based on assimilation, fermentation and morphology (Dembry et al., 1994). Given many limitations of phenotypic methods, molecular biology has been adapted for usage as definitive identification method (Williams et al., 1995).

Recent advances in the use of molecular DNA analysis have facilitated the development of identification system at a species level allowing earlier initiation of antifungal therapy and perhaps improved chance of survival (Cirak et al., 2003).

Different molecular methods have allowed the discrimination between closely related species like $C$. dubliniensis and C. albicans, C. orthopsilosis, C. metapsilosis and $C$. parapsilosis and $C$. nivariensis, $C$. bracarensis and $C$. glabrata. This discrimination may be of therapeutic importance for example, C. dubliniensis more easily develops fluconazole resistance than $C$. albicans (Mirhendi et al., 2011).

Among these methods, polymerase chain reactionrestriction fragment length polymorphism (PCR-RFLP), peptide nucleic acid-fluorescent in situ hybridization (PNA-FISH), random amplified polymorphic DNA-PCR, DNA sequence analysis and mitochondrial large subunit ribosomal RNA gene sequencing are reliable for typing purposes (Mirhendi et al., 2011, 2006).

Polymerase chain reaction (PCR) technology can directly detect the presence of fungi at high level of sensitivity and specificity. Moreover, RFLP is used for discrimination of the clinically important Candida species (Mirhendi et al., 2001).

The aim of this study was to identify and characterize the clinically isolated Candida species from fingernail onychomycosis by using genotypic method such as PCRRFLP analysis.

\section{MATERIALS AND METHODS}

Sixteen Candida isolates recovered from infected fingernail samples were evaluated for molecular relatedness using PCRRFLP. The clinical samples were collected from 45 female patients in Dermatology Outpatient Clinics of Mansoura University Hospitals with age that ranged from 31.3 to 45.6 years with past history of chronic paronychia and nail dystrophy during the period from April to August 2010.

Samples were cultured on Sabouraud dextrose agar (SDA) Oxoid] with chloramphenicol. Candida isolates were selected and phenotypically identified by colony morphology, germ tube formation and confirmed by semi-automated API 20C identification kit system (BioMerieux, Basingslakce limited kingdom).

\section{DNA extraction}

Genomic DNA of the tested Candida strains was extracted with the QIAamp tissue kit (Qiagen, Germany) according to manufacturer instructions for DNA extraction from yeast.

\section{Amplification}

The PCR designed by Williams et al. (1995) was used to amplify the entire internal transcribed spacer (ITS1-5.8SrDNA-ITS2) region of ribosomal DNA (rDNA) with the primers ITS1 (f5'-TCC GTA GGT GAA CGT GCG G-3') and ITS4 (r5'-TCC TCC GCT TAT TGA TAT GC-3'). For the optimum PCR conditions, a reaction volume of 100 $\mu \mathrm{l}$ contained $0.2 \mathrm{mM}$ each deoxynucleoside triphosphate, $1.5 \mathrm{mM}$ magnesium chloride, $0.5 \mu \mathrm{M}$ of each primer, 10x Taq buffer and $2.5 \mathrm{U}$ of Taq DNA polymerase and $0.5 \mu \mathrm{g}$ of candidal DNA as template were used. Reaction mixtures were subjected to 35 cycles of the following incubations: denaturation at $95^{\circ} \mathrm{C}$ for $1 \mathrm{~min}$, primer annealing at $55^{\circ} \mathrm{C}$ for $1 \mathrm{~min}$ and extension at $72^{\circ} \mathrm{C}$ for $2 \mathrm{~min}$. $10 \mu \mathrm{l}$ from the amplicons were analysed in $2 \%$ agarose gel with $1 \mathrm{x}$ TBE buffer stained with ethidium bromide and visualized by UV light.

\section{Restriction fragment length polymorphism}

The amplified PCR products (5 ul) were digested individually without further purification with 10 ul of restriction enzymes Haelll, Bfal, and Ddel (New England Biolabs, Hitchin, UK) by overnight incubation at $37^{\circ} \mathrm{C}$. The digested DNA products were subjected to electrophoresis on $2 \%$ agarose gel and DNA bands were visualised by UV trans-illumination (Nho et al., 1997).

\section{Statistical analysis}

The data were transferred to software SPSS version 12 and only age range was calculated accordingly in this study. The other parameters of the results were measured using the mathematical tools.

\section{RESULTS}

On the basis of assimilation profiles performed with API 20C, 16 Candida isolates revealed three species: $C$. albicans (9/16), C. parapsilosis (3/16) and C. glabrata $(1 / 16)$, with three unidentified isolates $(3 / 16)$ at this level (Table 1).

The intergenic spacer region was successfully amplified from all tested isolates using universal primers (ITS1 and ITS4) with production of a distinct product size. A product size of approximately $800 \mathrm{bp}$ was identified as C. glabrata, while a product of approximately $600 \mathrm{bp}$ was identified as C. guilliermondii. However, a product of 520 bp was obtained from the remaining isolates.

All isolates were further studied by RFLP analysis following digestion of PCR products by Haelll, Bfal and Ddel restriction enzymes.

On the basis of genotypic identification using PCRRFLP analysis, the tested 16 Candida isolates revealed 
Table 1. Comparison of Candida species identification $(n=16)$ by API $20 \mathrm{C}$ and PCR-RFLP.

\begin{tabular}{lcc}
\hline Candida species & API 20C & PCR-RFLP \\
\hline C. albicans & 9 & 9 \\
C. parapsilosis & 3 & 4 \\
C. glabrata & 1 & 1 \\
C. guilliermondii & - & 1 \\
C. tropicalis & - & 1 \\
\hline
\end{tabular}

Table 2. Sizes of the ITS1-ITS4 PCR products before and after digestion with the three restriction enzymes for different Candida species.

\begin{tabular}{|c|c|c|c|c|}
\hline \multicolumn{3}{|c|}{ Size of restriction products (number of bp) } & \multirow{2}{*}{$\begin{array}{c}\text { Size of PCR product } \\
\text { (number of bp) } \\
\end{array}$} & \multirow{2}{*}{ Candida species } \\
\hline Ddel & Haelll & Bfal & & \\
\hline $100-420$ & $90-430$ & - & 535 & C. albicans \\
\hline- & $40-110-390$ & - & 520 & C. parapsilosis \\
\hline- & $200-650$ & - & 871 & C. glabrata \\
\hline- & - & $394-234-120$ & 608 & C. guilliermondii \\
\hline- & - & $453-298$ & 524 & C. tropicalis \\
\hline
\end{tabular}

five species: C. albicans (9/16), C. parapsilosis (4/16), C. glabrata, C. guilliermondii and $C$. tropicalis (1/16 for each) as shown in Table 1.

Haelll restriction fragments were obtained for three species including C. albicans (two fragments, one at 430 $\mathrm{bp}$ and the other at $90 \mathrm{bp}$ which was slightly unstable and cannot be detected on agarose gel), C. parapsilosis (three fragments) and C. glabrata (two fragments). While, by using Bfal enzyme, the pattern of fragments was obtained for the remaining two species (three for $C$. guilliermondii and two for $C$. tropicalis). Two restriction fragments for $C$. albicans by using Ddel enzyme are shown in Table 2.

Isolates of $C$. glabrata and $C$. guilliermondii could be discriminated on the basis of their PCR product size alone while a characteristic profile following restriction enzymes digestion allowed the discrimination of the remaining isolates.

RFLP analysis demonstrated that Haelll was the most differentiating enzyme. Restriction Haelll enzyme was definitive for distinguishing $C$. albicans species from non C. albicans species. Restriction Bfal was found to be useful in the differentiation of these non albicans species. Restriction Ddel digestion confirmed C. albicans species which yielded 100 and $420 \mathrm{bp}$.

\section{DISCUSSION}

Identification of pathogenic fungi has changed dramatically over the past decade through direct examination of the tremendous variations present in DNA (McEwen et al., 2000). Typing methods based on phenotypic characteristics are usually easy and cheap to perform but need to purify target organisms that are laborious, time consuming and they have shown a lack in their reproducibility (Shokohi et al., 2010).

On the contrary, genotypic methods are expensive and require sophisticated technology but they usually have good reproducibility (Del Castillo et al., 1997). Among these methods, karyotyping and PCR-based techniques are reliable for most typing purposes. Karyotyping is somewhat laborious and time consuming, while PCR methods provide an opportunity for typing that have rapid turnaround times. These methods can detect extremely small quantities of DNA with earlier detection of pathogenic fungi and consequently allow earlier beginning of antifungal therapy (Henry et al., 2000; Mirhendi et al., 2006).

There have been reports of several studies using PCR techniques together with restriction digestion enzymes for special identification of species that also expressed several techniques with universal primers for identification of various fungi. The ITS1 and ITS2 regions are surrounded by 5.8SrDNA gene. These regions are appropriate for diagnosis, identification, taxonomy and phylogeny of fungi which are medically important. Universal primers are usually used as a beneficial approach for clinical microbiological diagnosis (Chen et al., 2000; Mirhendi and Makimura, 2003).

Sequencing the D1/D2 domain of the large subunit RNA gene and ITS1 and ITS2 regions of the ribosomal 
DNA have proven to be useful for the DNA-based identification of most fungi. These targets have been the basis of the discovery of new pathogenic yeast species and Iwen et al. (2002) concluded that 5.8S rDNA-ITSRFLP is the best method for rapid and accurate identification of yeast species. Sequence analysis of the ITS region suggesting many restriction enzymes are suitable for RFLP differentiation of Candida species (Mirhendi et al., 2011).

RFLP is based on the digestion of DNA. Every organism possesses unique nucleotide sequences that distinguish it from every other organism on the basis of the number and size of the fragments. DNA is extracted from isolates and cleaved into fragments by restriction endonucleases then the fragments are separated by gel electrophoresis (Taylor et al., 1999). RFLP requires only a moderate time and work; the method has been used for genotyping a variety of pathogens within the last few years (Taylor et al., 1999).

The present study has shown that five medically important Candida species (C. albicans, C. parapsilosis, C. glabrata, C. guilliermondii and C. tropicalis) were isolated from fingernail onychomycosis and can be distinguished on the basis of size and structural differences in rDNA spacer regions.

These isolates were matched with those isolated by Upton et al. (2004) who, with exception of isolation of $C$. glabrata, confirmed the importance of $C$. parapsilosis as an emerging non albicans species causing fingernail onychomycosis.

As reported by several previous studies (Dembry et al., 1994; Mirhendi et al., 2001), not only C. glabrata but also, C. guilliermondii could be discriminated on the basis of their PCR product size alone. Our study discriminated only one isolate for each of $C$. glabrata and $C$. guilliermondii that was further identified by using restriction enzymes, Haell for $C$. glabrata and Bfal for $C$. guilliermondii giving a characteristic profile.

RFLP analysis of the PCR products with the three restriction enzymes used in this study allowed us to identify the five most medically important Candida species. The differences in the restriction patterns for the rDNA regions of the various Candida species serve as a rapid means of differentiation among these organisms. Haelll enzyme is definitive for distinguishing C. albicans species from non $C$. albicans species. Bfal is found to be useful in the differentiation of these non $C$. albicans species, while Ddel digestion seems to be efficient to identify C. albicans species.

Haelll restriction fragments were obtained for three species including $C$. albicans (two fragments), $C$. parapsilosis (three fragments) and C. glabrata (two fragments) while, by using Bfal enzyme, the pattern of fragments was obtained for the remaining two species (three for C. guilliermondii and two for C. tropicalis. Two restriction fragments for $C$. albicans by using Ddel enzyme are shown.

Our identification profiles of these Candida isolates based on RFLP with the previous three endonucleases were similar to those obtained by previous investigators (Ayatollahi et al., 2007; Mirhendi et al., 2011). Williams et al. (1995) demonstrated the same three restriction fragments produced by Bfal enzyme for $C$. guilliermondii species as in the present study.

On the other hand, all strains identified with API 20C as C. albicans $(9 / 16)$ produced characteristic amplification product size and confirmed by the use of Ddel enzyme giving rise to $100 \%$ concordance between the conventional and PCR-RFLP methods.

Three strains of $C$. parapsilosis $(3 / 16)$ were identified with API 20C versus four strains (4/16), produced characteristic amplification products and confirmed by the use of Haelll giving rise to $75 \%$ agreement between the two methods.

Such results are in agreement with the data reported by Chen et al. (2001) and Baires-Varguez et al. (2007). In a previous study done by Chen et al. (2000), it was found that more than $98 \%$ concordance was between biochemical and ITS2 genotypic identifications validated with over 400 clinical yeast isolates.

Study limitations for the remaining three species $C$. glabrata, C. guilliermondii and C. tropicalis were carried out due to small number of these isolates (one for each). Hence, larger numbers of isolates are needed to evaluate the concordance between the two methods.

In conclusion, PCR-RFLP analysis of rDNA enabled more easy, rapid and precise identification of Candida species when compared with the phenotypic methods. RFLP analysis demonstrated that Haelll is the most differentiating enzyme that distinguished $C$. albicans from non $C$. albicans species while, Bfal maintained the differentiation of these non C. albicans species and Ddel digestion confirmed the $C$. albicans species.

\section{REFERENCES}

Ayatollahi Mousavi SA, Khalesi E, Shahidi Bonjar GH, Aghighi S, Sharifi F, Aram F (2007). Rapid molecular diagnosis for Candida species using PCR-RFLP. Biotechnology 6:583-587.

Baires-Varguez L, Cruz-García A, Villa-Tanaka L, Sánchez-García S, Gaitán-Cepeda, LA, Sánchez-Vargas LO, Quindós G, HernándezRodríguez C (2007). Comparison of a randomly amplified polymorphic DNA (RAPD) analysis and ATB ID 32C system for identification of clinical isolates of different Candida species. Rev. Iberoam. Micol. 24(2):148-151.

Chen YC, Eisner JD, Kattar MM, Rassoulian-Barrett SL, Lafe K, Bui U, Limaye AP, Cookson BT (2001). Polymorphic internal transcribed spacer region 1 DNA sequences identify medically important yeasts. J. Clin. Microbiol. 39(11):4042-4051.

Chen YC, Eisner JD, Kattar MM, Rassoulian-Barrett SL, Lafe K, Yarfitz SL (2000). Identification of medically important yeasts using. PCRbased detection of DNA sequence polymorphisms in the internal transcribed spacer 2 region of rRNA genes. J. Clin. Microbiol. 38(6):2302-2310.

Cirak MY, Kalkanci A, Kustimur S (2003). Use of molecular methods in 
identification of Candida species and evaluation of fluconazole resistance. Mem. Inst. Oswaldo Cruz. 98(8):1027-1032.

Del Castillo L, Bikandi J, Nieto A, Quindos G (1997). Comparison of morphotypic and genotypic methods for strain delineation in Candida. Mycoses 40(11-12):445-450.

Dembry LM, Vazquez JA, Zeros MJ (1994). DNA analysis in the study of epidemiology of nosocomial candidiasis. Infect. Control Hosp. Epidemiol. 15(1):48-53.

Ghannoum MA, Hajjeh RA, Scher R (2000). A large scale North American study of fungal isolates from nails. The frequency of onychomycosis, fungal distribution and antifungal susceptibility patterns. J. Am. Acad. Dermatol. 43(4):641-648.

Henry T, Iwen PC, Hinirchs SH (2000). Identification of Aspergillus species using internal transcribed spacer region 1 and 2. J. Clin. Microbiol. 38(4):1510-1515.

Iwen PC, Hinrichs SH, Rupp ME (2002). Utilization of the internal transcribed spacer regions as molecular targets to detect and identify human fungal pathogens. Med. Mycol. 40(1):87-109.

Jayatilake JA, Tilakaratne WM, Panagode GJ (2009). Candida onychomycosis: a mini-review. Mycopathologia 168(4):165-173.

McEwen JG, Taylor JW, Carter D, Xu J, Felipe MS, Vilgalys R, Mitchell TG, Kasuga T, White T, Bui T, Soares CM (2000). Molecular typing of pathogenic fungi. Med. Mycol. (Suppl.1)38:189-197.

Mirhendi H, Bruun B, Schonheyder HC, Christensen JJ, Fuursted K, Gahrn-Hansen B, Johansen HK, Nielsen L, Knudsen JD, Arendrup MC (2011). Differentiation of Candida glabrata, C. nivariensis and $C$. bracarensis based on fragment length polymorphism of ITS1 and ITS2 and restriction fragment length polymorphism of ITS and D1/D2 regions in rDNA. Eur. J. Clin. Microbiol. Infect. Dis. 30(11):14091416.

Mirhendi H, Makimura K (2003). PCR-detection of C. albicans in blood using a new primer pair to diagnosis of systemic candidiasis. Iran. J. Publ. Health 32:1-5.

Mirhendi SH, Kerdbacheh P, Karemi B, Samiei S, Pezeshhi M, Khorramizadeh M (2001). A PCR-RFLP Methods to identification of the important opportunistic fungi: Candida species, Cryptococcus neoformans, Aspergillus Famigatus and Fusarium solani. Iran. J. Publ. Health 30(3-4):103-106.
Mirhendi SH, Makimura K, Khoramizadeh M, Yamaguchi H (2006). A one-enzyme PCR-RFLP assay for identification of six medically important Candida species. Nihon Ishinkin Gakkai Zasshi. 47(3):225229.

Nho S, Anderson MJ, Moore CB, Denning DW (1997). Species differentiation by internally transcribed spacer PCR and Hhal digestion of fluconazole-resistant Candida krusei, Candida inconspicua, and Candida norvegensis strains. J. Clin. Microbiol. 35(4):1036-1039.

Roberts DT, Taylor WD, Boyle J (2003). Guidelines for treatment of onychomycosis. Br. J. Dermatol. 148(3):402-410.

Shokohi T, Hashemi S, Saltanat P, Hedayati M, Mayahi S (2010). Identification of Candida species using PCR-RFLP in cancer patients in Iran. Indian J. Med. Microbiol. 28(2):147-151.

Taylor JW, Geiser DM, Burt A, Koufopanou V (1999). The evolutionary biology and population genetics underlying fungal strain typing. Clin. Microbiol. Rev. 12:126-146.

Upton A, Rogers K, Wood N, Morris AJ (2004). Antifungal susceptibility of non-albicans Candida species causing fingernail onychomycosis. N. Z. Med. J. 117(1201):U1060.

Williams DW, Wilson MJ, Lewis MAO, Potts AJ (1995). Identification of Candida species by PCR and restriction fragment length polymorphism analysis of intergenic spacer regions of ribosomal DNA. J. Clin. Microbiol. 33:2476-2479. 